\title{
ENCUENTROS EN UN ESPACIO GEOGRÁFICO: ANTROPOLOGÍA Y LITERATURA
}

\author{
Encounters in a Geographic Space: Anthropology and Literature \\ Carlos Gutiérrez Alfonzo* \\ DOI: http://dx.doi.org/10.29043/liminar.v19i2.841
}

\begin{abstract}
Resumen: Situado en el vértice de los Altos Cuchumatanes y la Sierra Madre de Chiapas, interesa asentar en este texto la forma en que, mediante antropología y literatura, ha habido hallazgos a la hora de leer un espacio geográfico; además, atraído por las conexiones entre estas disciplinas, se consigna cómo en los años ochenta del siglo veinte, como parte de un proyecto histórico y antropológico, la literatura fue una fuente para observar esta región del país; luego, se exponen ejemplos extraídos de textos literarios que hacen referencia a ese tramo de la frontera, la cual fue definida en 1882 por los Estados nacionales de México y Guatemala. Este ejercicio tiene el interés académico de ir precisando una antropología de la literatura en la frontera.
\end{abstract}

Palabras clave: discursos literarios, antropología literaria, fronteras.

Abstract: Located at the vertex of the Cuchumatanes highlands and the Sierra Madre of Chiapas, in this text we are interested in establishing the way in which, through anthropology and literature, discoveries have been made when reading a geographical space; furthermore, attracted by the connections between these disciplines, we discuss how in the 1980s, as part of a historical and anthropological project, literature was a source to observe this region of the country. We then take examples from literary texts that refer to this particular stretch of the border, which was defined in 1882 by the national states of Mexico and Guatemala. This exercise has an academic interest in that it deepens understanding of an anthropology of literature on the border.

Key words: literary discourses, literary anthropology, border.

\footnotetext{
* Carlos Gutiérrez Alfonzo. Doctor en humanidades y artes por la Universidad Autónoma de Zacatecas, México. Investigador del Centro de Investigaciones Multidisciplinarias sobre Chiapas y la Frontera Sur (CIMSUR) de la Universidad Nacional Autónoma de México (UNAM), México. Temas de especialización: literatura y cultura. Correo electrónico: carlosalfonzo6@gmail.com. ORCID: https://orcid.org/0000-0001-7810-6030
}

Enviado a dictamen: 21 de septiembre de 2020 Aprobación: 31 de octubre de 2020 
L a intención académica ${ }^{1}$ que se expone en las siguientes páginas —en el entendido de que la "mayoría de las veces no tenemos una noción exacta de lo que estamos buscando; nada más estamos buscando. Intuimos [...] que debe haber algo ahí" (Davenport, 2008:161) - está guiada por la determinación de escribir sin separar antropología y literatura, una relación que en Chiapas tiene claros ejemplos (Morales Bermúdez, 1994), si se piensa pronto, por lo menos, en Ricardo Pozas (Medina, 1994), y si se abre el espectro aparece la figura descrita por Clifford Geertz: El antropólogo como autor (1997). Ese propósito está marcado por intuiciones, las que apuntan hacia el hecho de que quien escribe lo que hace es, sobre todo, narrar, interpretar aquello que ha elegido al observar una colectividad o unos libros. De unos años para acá, ese designio, con la intensidad del caso, se ha circunscrito a un espacio geográfico, provocador de una anagnórisis personal (Gutiérrez Alfonzo, 2018).

Las referencias sobre el vértice descubierto se fueron aquilatando con el paso de los años, en los que se podría hablar de temporadas de campo durante las vacaciones de Semana Santa, en las del verano y en las de diciembre, y en las que de acuerdo con las situaciones políticas del entorno hubo momentos de efervescencia, como cuando a ese espacio llegó población guatemalteca, la que huía de su patria porque se le deseaba exterminar (Kauffer, 1997).

El material antropológico se tornó en una masa informe que dio lugar a preguntas, sin avizorar respuestas. O más bien, quieto, se veía esa agitación social; nunca fue central llevarla a las aulas, hacerla motivo de investigación. Quizá en ese momento, quien se obnubilaba estaba más cerca de la literatura. Sin pensarlo, encaminó sus pasos hacia lo que había reconocido como su afición, la asistencia a talleres literarios, a los que había sido afecto cuando se preguntó sobre sus inquietudes intelectuales, al principio de sus estudios de preparatoria. De esa manera se dio el encuentro de las dos disciplinas, antropología y literatura, con las que descubrió que era posible dar cuenta de una labor.
La antropología hizo que se revelara un punto geográfico. La literatura le ayudó a saber que tenía una mina en las manos, sus manos; le había enseñado a oír, a hallar yacimientos en el polvo de todos los días. La máquina de coser y el paraguas que necesitaba para percibir dónde estaba parado. El reconocimiento de cuanto habría de portar, en la conjunción de ambas disciplinas, ocurrió varios años después de haber abandonado el sitio en el que se dio su encuentro con las voces de la Sierra, las que estaban inmersas en un torrente que en ocasiones era ahogado por el trabajo burocrático. La eterna duda que le lleva a tirar lo que logra colocar en sus manos, con la que ha batallado siempre, le dejó atisbar lo que su maestro le impuso como una obligación: cuidar cada una de sus palabras, que cada una provocara la exaltación del ánimo.

La asunción del compromiso con la palabra le permitió que oyera como había aprendido a oír, cuando su infancia, las lluvias de su pueblo. Ese agudo interés lo condujo a leer relatos del lugar que estaba por definir. Una vez que pudo ubicarlos dentro de la corriente de voces en la que se encontraban, vio su construcción (elementos mitológicos y estilísticos, sus frases, su vocabulario). Los colocó como parte de la literatura de México y los analizó, mediante el contraste de motivos, con otros pertenecientes a ese espacio que se ha denominado Mesoamérica (Gutiérrez Alfonzo, 2010).

Una vez que vislumbró los parámetros por los que habría de conducirse, y como parte de un proyecto colectivo, que tenía como objetivo conocer "el norte y el sur de México en la diversidad de su literatura" (Cuevas Velasco y Velasco González, 2011), dio un panorama de la literatura de Chiapas y vio las migraciones y las fronteras en términos de la lengua, de las lenguas, y de la elaboración artística de la castilla (Morales Bermúdez, 1987). En una segunda incursión, ubicado en la frontera Chiapas-Guatemala, detectó que la enunciación en primera persona ha sido el recurso privilegiado para la tematización de la vida de la frontera sur.

Se ha querido observar una frontera fructífera, un espacio rico en experiencias sociales y culturales que van dándole rostro a una cotidianeidad. Con esta posición, se propuso analizar discursos en torno a habitar en la 
frontera, enfocado en la región de Frontera Comalapa, y se analizó la frontera Chiapas-Guatemala con base en la antropología (Gutiérrez Alfonzo, 2017). Tanto el área de estudio como los discursos generados en ella o a partir de ella son fuentes inagotables con miras a la construcción de conocimiento, así se descubre al dilucidar los datos recopilados. Atrae observar cómo quien habla construye de manera verbal esas realidades por las que se siente atrapado; realidades que seducen.

Poco a poco fueron apareciendo las bases que permitían que fusionara antropología y literatura, entre las cuales han estado los discursos. Ha vislumbrado que los discursos que son de su interés pudieron ser escritos por personas cuya intención solo era expresar un presente mediante la descripción de situaciones provocadas por vivir en la frontera o por haber experimentado procesos de migración, sin mayores pretensiones; o por quienes los escribieron con el deseo de verlos publicados fuera de su propio ámbito y los presentaron con pretensiones literarias. En las dos formas, ha observado que se construye un presente en el que la frontera marca la dimensión de lo humano. Están, entonces, en el horizonte de sus búsquedas dos tipos de discursos: los testimoniales y los literarios. Los discursos pueden aparecer como un solo texto, exhibidos como tales, o dentro de un reportaje periodístico, una crónica, un diario o una etnografía.

El ser humano actúa a partir de intencionalidades, y dentro de estas se encuentra la elaboración de discursos: "como los textos son cristalizaciones de actos discursivos, su realidad [la de los textos] es constitutivamente intencional" (Schaeffer, 2013:63). Estas cristalizaciones discursivas, que han sido objeto de estudio de las Humanidades, o también llamadas ciencias humanas, son autorreferenciales, pues están sujetas a interpretaciones. "Las ciencias humanas se ocupan esencialmente de hechos de significación, de hechos que hay que comprender e interpretar, de hechos que están sometidos a la jurisdicción de una hermenéutica" (Schaeffer, 2013:82).
Lo que interesa estudiar es la intencionalidad convertida en texto, en donde la pregunta no va dirigida a tratar de interpretar lo que quiso decir el autor. Se va por esta línea: "leer es atribuir una significación a enunciados; y atribuir una significación a enunciados es atribuir a dicha significación al querer-decir del enunciador, o sea, ubicar a alguien que ha querido decir lo que comprendemos como lo que está dicho" (Schaeffer, 2013:91). Y la comprensión de lo que ha sido dicho en el texto atraviesa por ser partícipe de un marco en el que, por principio de cuentas, importa el conocimiento de la lengua en la que se ha escrito el texto y que el lector tenga la competencia para dejarse atrapar por los recursos utilizados por el autor, por sus componentes semánticos. Están acá expuestas las consideraciones, que siempre están en relación, que deben tenerse en cuenta al estar frente a discursos: "la configuración del autor, la encarnación textual y la reconfiguración del lector" (Schaeffer, 2013:99).

Al estar trabajando en este campo de conocimiento se procura delinear ideas que pudieran estar en el trasvase de la historia cultural de esta región, una manera de "reflexionar sobre lo humano desde lo literario" (Díaz Viana, 2008:81).

Esta exigua descripción de cómo afrontar el objeto de estudio - discursos que son "una ejemplificación virtual de un ser-en-el mundo posible" (Schaeffer, 2013:107) — es para enfatizar cómo en las Humanidades, sobre todo en el estudio de discursos, son definidos los parámetros de análisis. Y como se trata de un proceso de comprensión es crucial el reconocimiento de lo que se ha analizado en la región de estudio, la frontera Chiapas-Guatemala, respecto a los discursos literarios; son mínimas las investigaciones en esta dirección.

La frontera sur sigue siendo un espacio inexplorado para las Humanidades. Han sido escasos los estudios acerca de esa área a partir de ese campo. Cuando el sur de México y su límite con Guatemala se convirtieron en objeto de estudio de las ciencias sociales, en especial de la antropología, en los años ochenta del siglo pasado, 
hubo dentro de ese proyecto inicial impulsado por el Centro de Investigaciones y Estudios Superiores en Antropología Social (CIESAS), la exploración somera de la novela histórica del siglo XIX y del relato popular existentes en la región.

Literatura, relato popular y religiosidad en el sureste de México (Díez-Canedo, Martínez y Tappan, 1985) fue un libro producto de esa tentativa. ${ }^{2}$ Está formado por tres artículos. ${ }^{3}$ El escrito por Aurora Díez-Canedo ("Dos novelas históricas del siglo XIX en el sureste de México. Lágrimas del corazón y Antón Pérez") es una descripción ligera de dos novelas; las vio a la luz de la novela histórica. Fueron escritas por autores reconocidos por ella como "representantes de la novela del siglo XIX en el sureste de México" (Díez-Canedo, 1985:3); uno de Chiapas (Flavio Antonio Paniagua) y otro de Yucatán (Manuel Sánchez Mármol). La autora se interesó por caracterizar las novelas y por encontrarles puntos en común. Sintetizó el argumento de cada una de ellas y caracterizó a los personajes principales.

Jorge Mario Martínez, en ese mismo libro, publicó el texto titulado "El conejo Juan y otros relatos (una contribución al estudio de lo cómico en la narrativa popular mesoamericana)". El interés del autor se centró en hacer una contribución para el estudio de una "Estética de la narrativa popular mesoamericana" (Martínez, 1985:39). Para ello, se inclinó hacia la elaboración de una tipología con base en unos cuantos relatos que encontró en Yucatán, en donde pudo acceder a relatos publicados en Guatemala. Se trató de un material "que no obedece a una intención específica puesto que únicamente reunimos lo que pudimos tener a la vista sin intención de agotar, ni mucho menos, el material publicado" (Martínez, 1985:39). No estuvo en su horizonte buscar el origen de los relatos; más bien, se enfocó en encontrar en los textos seleccionados "el tipo narrativo y la forma en que está compuesto el argumento” (Martínez, 1985:43). Es el análisis del argumento el que podrá ayudar a comprender los relatos de extracción oral, y conocer las transformaciones de estos puede ser una clave para "entender el lado oculto de la narrativa popular mesoamericana" (Martínez, 1985:77).
Los acercamientos citados antes poseen líneas generales para la investigación humanística de un espacio que en ese libro no fue reconocido como frontera sur, aunque su auspicio haya estado a cargo del Programa Cultural de las Fronteras. En ambos casos, se tuvo como objeto de estudio textos que fueron leídos de acuerdo con los intereses de cada investigador. El universo explorado es mucho más amplio que el que se consignó en los dos artículos. Una mirada rápida, a partir de la incursión en algunos archivos, deja ver el material que se publicó durante el siglo XIX en Chiapas, por ejemplo (Morales Bermúdez, 1997). Y para el caso de los relatos orales aparecidos en libros o revistas, los antropólogos tuvieron una labor crucial para darlos a conocer. Abundante material. Escasa investigación en esta vertiente.

Las condiciones sociales y económicas de Chiapas, cuya frontera con Guatemala abarca el 57.3\% del total de la frontera sur, provocaron que las investigaciones sociales y ambientales se convirtieran en el eje de la generación de conocimiento respaldado por instituciones gubernamentales. Se ha creído apremiante que los especialistas entreguen explicaciones sobre las problemáticas que jalonean las realidades de la entidad. Y para ello han elegido como objetos de estudio organizaciones civiles, movimientos sociales, agrupaciones identificadas con alguna reivindicación étnica: se hace entrevistas, se consulta documentos, se entrega explicaciones sobre relaciones sociales incididas por procesos de globalización. Las recientes luchas por el territorio han atraído a investigadores sociales.

Entre estas construcciones explicativas de orden económico y social, la frontera Chiapas-Guatemala como objeto de estudio a partir de la literatura, sobre todo de la narrativa, la que con claridad muestra entramados sociales, se presenta como un universo explorado solo a grandes rasgos. Hacia el final de la primera década del siglo XXI, un grupo de investigadores de tres universidades estatales, comandado por un cuerpo académico del Instituto de Investigaciones Lingüístico-Literarias, de la Universidad Veracruzana, y con financiamiento de la Secretaría de Educación Pública, decidió estudiar las fronteras de México: el norte y el sur en la diversidad de su literatura (Cuevas Velasco y Velasco González, 
2011), en cuyo resultado de investigación se lee que se trató de recuperar "las constantes de una literatura edificada en los bordes de ese México que extiende las voces mesoamericanas provenientes incluso de lugares lejanos a su territorio — como Colombia y Panamá—al interior de Estados Unidos" (Cuevas Velasco y Velasco González, 2011:7). La investigación fue vista como un preámbulo, "una mirada a los escenarios donde figura la problemática de la frontera [y en donde fue] necesario cruzar fronteras en cuanto a límites — si así podemos llamarlos - de la literatura misma al atender textos no ficcionales" (Antonio Romero y Cuevas Velasco, 2011:206).

El panorama descrito incita a explorar discursos no ficcionales (testimonios) y ficcionales (literarios); convertirlos en objeto de estudio para observar cómo, o cómo no, se construye con palabras la frontera (Quijano, 2018:XXXIII). Este estímulo se genera porque se trata de un universo que ha sido dicho con notas iniciales, como un preludio, con la región de la selva chiapaneca como punto de atracción (Morales Bermúdez, 2005 y 2019). Colocarlo de nuevo a la vista de las Humanidades, como se hace en las líneas siguientes, implica abonar hacia una comprensión amplia de las especificidades de la zona, a partir de discursos literarios, con la mirada puesta hacia Guatemala, cuya historia, en uno de sus momentos, el de los años cincuenta, atrajo a Mario Vargas Llosa para escribir su novela reciente, Tiempos recios.

Habría que ser consciente de que la publicación en 2019 de una novela sobre un suceso de la historia de Guatemala, ocurrido en 1954, hace que se esté alerta. Hay imanes: el autor, la editorial y lo que significa poner los ojos ahora en ese hecho. Hay que situar la atención en que los materiales que interesan tienen características especificadas líneas arriba, y hay que comportarse con la conciencia de que siempre habrá estos vaivenes, este ir hacia un pasado para dar cuenta de realidades que pudieran seguir bullendo en este presente.

En la búsqueda de discursos sobre la frontera o en la frontera, se ha tenido hallazgos como los que se consignan en las siguientes páginas. Los que están expuestos en Balún Canán, novela de Rosario Castellanos editada por primera vez en 1957, fueron hechos conscientes gracias a la benevolencia del historiador Mario Vázquez Olivera (comunicación personal). Son precisas las referencias a la frontera política, sin perder de vista esta otra identificada por la narradora: "Me da miedo que del otro lado haya un espejo" (Castellanos, 1996:20), o las otras, como la del mundo de la niña y el mundo de los adultos.

En la cita siguiente, se amplía la definición del espacio en el que se está, y se le ubica en la frontera:

Ya se entablaron las aguas. Los caminos que van a México están cerrados. Los automóviles se atascan en el lodo: los aviones caen abatidos por la tempestad. Sólo las recuas de mulas continúan haciendo su tráfico entre las poblaciones vecinas, trayendo y llevando carga, viajeros, el correo.

Todos nos asomamos a los balcones para verlas llegar. Entran siguiendo a la mula madrina que hace sonar briosamente su cencerro. Vienen con las herraduras rotas, con el lomo lastimado. Pero vienen de lejos y traen noticias y cosas de otras partes. iQué alegría nos da saber que entre los cajones bien remachados y los bultos envueltos en petate vienen las bolsas de lona tricolor, repletas de periódicos y cartas! Estamos tan aislados en Comitán, durante la temporada de lluvias. Estamos tan lejos siempre. Una vez vi un mapa de la República y hacia el sur acababa donde vivimos nosotros. Después ya no hay ninguna otra ruedita. Sólo una raya para marcar la frontera (Castellanos, 1996:44).

Hay un centro en el que todo se controla. Y lejos de ahí, hacia el sur, no hay más que un punto y una raya. Una sensación de lejanía está presente. Y todo llega con dificultad, sobre todo, por las lluvias. Con los arrieros llegaban los periódicos y las cartas. Que de arrieros es la trama de Los arrieros del agua, de Carlos Navarrete (1984), quien en veintisiete capítulos da la voz a Reinaldo para que cuente su vida. Abandonada por el padre, la madre de Reinaldo no tuvo más que cederlo a su padrino, hom- 
bre dedicado a la arriería. Postrado, sin poder bailar en la fiesta de su pueblo, sin poder vestirse de parachico, resignado, "uno termina hablando solo, por más que se tenga fijo en la cabeza que ser chismoso es malo y peor serlo de uno mismo" (Navarrete, 1984:8), empieza a traer sus pasos, los cuales anduvieron por la depresión central, la sierra, la costa y la frontera con Guatemala.

Un punto de encuentro entre arrieros chiapanecos y arrieros guatemaltecos era Comitán, ese lugar aislado referido en la novela citada de Rosario Castellanos. Lo había sido desde mucho antes para vendedores de todo tipo, como se lee en el relato de Alfonso Reyes ubicado en 1830, sobre el súbdito alemán, quien ayudaba a vender telas finas y palillos de dientes:

Días después, salimos de Tonalá hacia Comitán, a rastra con nuestras telas y con nuestra almendra: el palillo. Doña Beatriz iba en lo más alto del carro, sobre unos bultos de seda, bamboleándose a cada tumbo. Don Jacintito, al lado del cochero. Y yo, a la par del carro, iba cabalgando en mi mula (Reyes, 1984:49).

Para Reinaldo, quien narra en Los arrieros del agua, los comerciantes guatemaltecos eran "indios mecapaleros", diferentes a los comerciantes chapines, quienes eran "una bola de presumidos enfundados en casimir grueso, de chaquetita, pantalón balón y botín-taconcito. Usaban faja y una bolsa de cuero de la que sacaban moneda pesada, dizque de águila gringa [...] Les gustaba tratar con ganado y telas; cambalacheaban café contra cacao y trago de olla por comiteco" (Navarrete, 1984:16-17).

Para Reinaldo, los comerciantes mecapaleros se comportaban de manera distinta a la que mostraban los comerciantes chapines. Eran personas respetuosas, quienes vendían ollas, telas y comales. Reinaldo los recuerda de esta forma:

Antes de entrar en Comitán se paraban en el último río a lavarse los pies y ponerse caites. En el punto donde están las cruces del camino real, ordenaban la mercancía y comenzaba el desfile del convite. Huelían a lana vieja [...] No dormían en mesón sino bajo los portales. Tampoco hablaban pendejadas, no hacían escándalo ni se iban con las putas. Tampoco traían espantos. Será porque eran indios y no hablaban castilla; tal vez por eso, pero yo sólo vi respeto entre los troperos y la gente de Comitán en la época en que nos afanábamos entre aquel bullicio en el mercado (Navarrete, 2018:17-18).

Se observa un afán marcado por la convivencia en espacios en los que los espantos están ausentes. La acogida de los arrieros debe estar bajo el amparo de Chiapaneco, según se cuenta por el Soconusco, en un relato recopilado por Carlos Navarrete en Tuxtla Chico, en 1966. Chiapaneco se movía por la frontera, y andaba pidiendo posada.

Las situaciones descritas tanto en Balún Canán como en Los arrieros del agua son ubicables en los años treinta del siglo XX, una década en la que las decisiones gubernamentales estuvieron encaminadas hacia la identificación de la población mexicana, mediante campañas de mexicanización; las escuelas tuvieron un lugar determinante en este proceso, sobre todo las que se encontraban en las poblaciones fronterizas, aquellas que, como se deja ver líneas arriba, en la cita de Balún Canán, no aparecían en el mapa. Es la década también en que Héctor Eduardo Paniagua, nacido en 1898, en el ahora municipio de Bellavista, ubicado en la Sierra Madre de Chiapas, publicó en la imprenta del gobierno del estado la compilación Fiesta de pájaros (Paniagua, 2011), el primer ejercicio para mostrar la producción poética de la entidad, con la idea también de que se viera hacia el exterior que se vivía con cierta calma.

A mediados de la década de los cuarenta del siglo $\mathrm{XX}$, entre la ruedita y la raya que marca la frontera, habría de construirse la Carretera Panamericana, que en su tramo final en el sur de México va, en 84.4 kilómetros, de la ciudad de Comitán a la línea, en la que del otro lado está la localidad de La Mesilla. Dos kilómetros antes de llegar a la línea, en el inicio de la Depresión Central de Chiapas, y antes de empezar a ascender por las montañas de Los Altos Cuchumatanes, localizados en Guatemala, se encontraba la población de El Ocotal, pequeño ejido del municipio de Frontera Comalapa. 
Con la idea de que hubiera una ruedita más en el mapa hacia la frontera, el gobierno federal decidió cambiarle el nombre a El Ocotal por el de Ciudad Cuauhtémoc; esto ocurrió en 1950, cuando se terminó la construcción de la carretera internacional "Cristóbal Colón", conocida también como Carretera Panamericana, un hecho que debía mostrarse como relevante no solo con la idea de que en el sur de México debía haber una ciudad, aunque solo fuera de nombre, sino también con la promoción del uso de vehículos automotores. Había que dejar las bestias, que eran utilizadas como transporte de carga y personas, por los camiones, por los automóviles. La carretera internacional se puso en servicio "con el importante evento de la Carretera Panamericana 'México' [...] tocando como punto final el citado poblado fronterizo". ${ }^{4}$ En ese tiempo de impulso al uso de los vehículos automotores, Juan Rulfo trabajaba en la llantera Goodrich-Euzkadi. Cristina Rivera Garza hizo viajar a Rulfo, en 1950, de Ciudad Juárez, Chihuahua, a El Ocotal, Chiapas, en automóvil, como puede leerse en el libro Había mucha neblina o humo o no sé qué (Rivera, 2016).

La de los cincuenta, década que se quiso como de la modernidad, en México, la del golpe de Estado en Guatemala, la del grupo Saker-Ti, formado por artistas y revolucionarios guatemaltecos, en el que estuvo Carlos Navarrete; la década que provocó la llegada a nuestro país de escritores e intelectuales, como Alaíde Foppa, Luis Cardoza y Aragón (por segunda ocasión), Carlos Illescas, Otto Raúl González, Mario Monteforte Toledo y Carlos Navarrete. Antes, en los cuarenta, había llegado Augusto Monterroso, exiliado en México también por motivos políticos.

En los años ochenta cruzarían la frontera mexicana una gran cantidad de guatemaltecos que huían de la represión en su país; la mayoría tendría la categoría de refugiados. A partir del siglo XXI, por el lado del Soconusco, serán mayoritarios los desplazamientos de centroamericanos, de El Salvador y Honduras, hacia México, a quienes "Nos parecemos mucho, es cierto. Tenemos casi las mismas facciones, el mismo brillo grasoso en la cara. Alguna mueca. Pero si algo los distingue es el pánico con el que ven, hablan, caminan. Eso ha de ser. Huyen" (Villafuerte, 2008:41).
Un pánico rastreable en las huidas que han sido vividas en los períodos mencionados antes; un pánico perceptible en la voz de Carlos Navarrete, cuando cuenta cómo fue echado en la frontera, casi moribundo, a la altura de los Lagos de Montebello, de la zona arqueológica de Chinkultic, adonde volvió para explorar como arqueólogo ese sitio relevante en la zona. Un pánico que podría desaparecer si se tomaba en cuenta la recomendación que recibieron, al llegar a la frontera, por el lado de Tapachula, Luis Cardoza y Aragón y sus amigos con quienes venía huyendo:
El 20 de octubre de 1944 estalló la revolución que estaba transformando a Guatemala, y el 22 crucé la frontera. Un avión nos dejó en Tapachula, México. El piloto quería prevenirnos y no inquietarnos a la vez. Se hallaba preocupado, y creo que al siguiente día leyó la prensa con el temor de encontrar en ella alguna trágica noticia relacionada con nosotros. Al despedirnos, la sencillez de su hombría encontró, mexicanamente, las palabras justas. Nos dijo con llaneza y con calor: "Procuren que no se los lleve la tiznada..." (Cardoza y Aragón, 1986:9).

Esa ciudad, "una ciudad no lejana - término de la tierra habitable- que responde al almibarado nombre de Tapachula" (Reyes, 1984:45), donde Felipe, personaje de Balún Canán, aprendió a leer y escribir, "después de conocer a Cárdenas" (Castellanos, 1996:90), en donde supo mediante un "papel que habla [...] que nosotros somos iguales a los blancos” (Castellanos, 1996:87), esa ciudad, Tapachula, es la que ahora atrae la atención por la cantidad de migrantes que ha recibido en los últimos años.

Las indagaciones descritas fueron hechas con base en textos observados mediante la firme convicción de que: "Si bien ya resulta un lugar común afirmar que los procesos literarios no pueden entenderse desligados del mundo político, social, e ideológico del que surgen, tampoco podemos siempre afirmar que los cambios 
políticos y los cambios artísticos van de la mano y suceden y expresan al mismo tiempo" (Martínez Luna, 2018:4). Se continúa con esta labor, la que se enmarca en conjeturas relacionadas con la frontera política y con lo que se vive en el punto de estudio. Para pensar la frontera política, se recurre de nuevo a un fragmento de Balún Canán:

—Dile a tu marido que puedo venderle lo que necesita.

-¿Qué?

-Un secreto.

¿Un secreto?

-Un lugar en la frontera. No hay guardias. Es fácil cruzarlo a cualquier hora. Dile que si me paga le muestro dónde es.

Mi madre sonríe creyendo que escucha una broma. - César no le va a hacer la competencia, doña Pastora. No piensa dedicarse al contrabando.

Doña Pastora mira a mi madre y repite, como amonestándola:

-Dile lo que te dije. Para cuando sea necesario huir (Castellanos, 1996:48).

La frontera como un lugar sin vigilancia, que solo es conocido por alguien que lo transita, una idea que pudiera aún ser parte de la definición de este espacio geográfico. Y para lo que ocurre ahí, donde se está situado, se ha elegido un fragmento del Manual del distraído: "Cónsules y Agentes Migratorios han sido, en este siglo de persecuciones y asesinatos, personajes infinitamente importantes. Pueden condenar o salvar. Como siempre, ha habido de todo. Casos ilustres y porquerías inolvidables. Unos agentes franquistas intentaron extorsionar a Walter Benjamin y sólo lograron que se suicidara" (Rossi, 1996:64).

Puede haber tramos sin vigilancia y tramos vigilados; no puede tenerse la idea de que todo responde a las mismas condiciones. Puede haber servidores públicos que tienen posiciones encontradas sobre lo que debe ser su trabajo en la franja fronteriza. Y como parte de las conjeturas, se anota una definición del sur: "En el sur están los pueblos proclives a la pobreza, a la ignorancia"
(Villafuerte, 2008:29). ¿Se trata de una condena? ¿Existe una salida? Habría, como se ha tratado de mostrar, maneras de enfrentarse a algo. Se elige esta: "la pobreza, la enfermedad y el fracaso y hasta la muerte podían ser soportables y aun bellos si uno se mantenía fiel al amor, a la amistad y, naturalmente, sobre todas las cosas, al arte" (Monterroso, 1993:103).

Quien vio cómo podían ser soportables condiciones lacerantes, hubo de saber cómo se podía ir hacia otros lados: "El pequeño mundo que uno encuentra al nacer es el mismo en cualquier parte en que se nazca; sólo se amplía si uno logra irse a tiempo de donde tiene que irse, físicamente o con la imaginación" (Monterroso, 1993:19). Cuando haya que huir, hay secretos, según se ha mostrado en este texto.

Existe otra idea sobre la región que se estudia, la de la existencia de una continuidad cultural entre Chiapas y Guatemala. Esa idea está expresada al final de la carta de Augusto Monterroso, que se cita a continuación, escrita el 6 de octubre de 1994, en Ciudad de México, con su puño y letra, en hoja de papel bond, tamaño esquela; en el extremo izquierdo está impreso su nombre. La carta llegó a Frontera Comalapa el 19 de octubre de 1994, por medio del servicio postal mexicano:
Estimado amigo:
Con gran pena contesto con tanto retraso su carta ide junio! Pero estuve una larga temporada fuera de México y todas mis cosas han sufrido el correspon- diente retraso. De veras, discúlpeme [...] Qué bueno que compartamos el gusto por la literatura, la música y la convivencia familiar [...] Nos preocupa todo lo de Chiapas, casi mi tierra.

Con la carta, se tiene el reconocimiento que el escritor hizo de Chiapas y Guatemala como parte de un mismo espacio, sin que medie frontera política alguna. Sintió el lado mexicano como propio. Está también el nomadismo que fue parte de su vida — nacido en Honduras ["Cuestión de tiempo y azar" (Monterroso, 1993:15)], se sintió guatemalteco- - un nomadismo reconocible en los textos citados en este artículo, provocado en varios de los casos por cuestiones políticas, como le ocurrió al 
mismo escritor que por salvar su vida debió exiliarse en México; al estar acá, fue hacia varios países impelido por la aceptación que tuvo su propuesta literaria.

Incitado por percepciones, las cuales se han acomodado como si de un rompecabezas se tratara, se descubrió un espacio geográfico y se decidió modelar procedimientos de la antropología y la literatura. Resultados de esta conjunción fueron descritos en este artículo: se observó cómo la literatura estuvo entre las institucionales inquietudes antropológicas cuando se dio el reconocimiento de la frontera sur; se expusieron asertos sobre la frontera, sobre quienes la han habitado en uno de sus tramos y sobre quienes la han transitado; el objeto de estudio fue el de los discursos literarios, de los que se aventuró una definición. Situado en un punto territorial, con antropología y literatura para estudiar discursos literarios, está la pretensión de ir reuniendo rasgos, motivos, acontecimientos, con los que se alcance la definición de una antropología de la literatura en la frontera. El de ahora es un ensayo que conduce hacia ese propósito. Las búsquedas continúan, "en un cielo de peculiar cuarentena" (Gornick, 2018), a la caza de los materiales, con el auxilio de las ideas antes detalladas.

\section{Notas}

${ }^{1}$ El autor agradece a Crystel Sofía Díaz, Ana Alejandra Robles Ruiz, Fortino Corral Rodríguez, Jesús Morales Bermúdez, Ruth Villalobos Villarreal y Claudia Morales por las sugerencias que hicieron para llegar a la versión que ahora se publica, y a quienes tuvieron la gentileza de dictaminar este texto. A la memoria de Efraín Ascencio Cedillo.

${ }^{2}$ El libro fue incluido en la serie Frontera Sur, vol. 3, coordinada por el antropólogo Andrés Fábregas Puig. Entre la página legal y el índice está la siguiente nota: "Esta investigación ha sido financiada por el Programa Cultural de las Fronteras y realizada por el Centro de Investigaciones y Estudios Superiores en Antropología Social, bajo la coordinación del maestro Andrés Fábregas".
${ }^{3}$ El tercer artículo se titula "Las manifestaciones mágicoreligiosas. El caso de los Altos de Chiapas”, escrito por José Eduardo Tappan Merino. Es un trabajo antropológico con base en material de campo.

${ }^{4}$ Cuaderno municipal, 002:317.

\section{Referencias}

Antonio Romero, Dahlia y Norma Angélica Cuevas Velasco (2011). "Territorios de la frontera sur en la narrativa mexicana: historias de migrantes". En Norma Angélica Cuevas Velasco y Raquel Velasco González (coords.), El norte y el sur de México en la diversidad de su literatura. México: Juan Pablos Editor, pp. 181-208.

Cardoza y Aragón, Luis (1986). Guatemala: Las líneas de su mano. México: Fondo de Cultura Económica.

Castellanos, Rosario (1996). Obras I. Narrativa. México: Fondo de Cultura Económica.

Cuevas Velasco, Norma Angélica y Raquel Velasco González (coords.) (2011). El norte y el sur de México en la diversidad de su literatura. México: Juan Pablos Editor.

Davenport, Guy (2008). ¿Qué son las revoluciones? Y otros ensayos sobre arte y literatura. Traducción y prefacio de Gabriel Bernal Granados. México: Libros Magenta.

Díaz Viana, Luis (2008). Narración y memoria. Anotaciones para una antropología de la catástrofe. Madrid: Universidad Nacional de Educación a Distancia.

Díez-Canedo, Aurora, Jorge Mario Martínez y Jorge Eduardo Tappan (1985). Literatura, relato popular y religiosidad en el sureste de México. México: CIESAS Sureste, Cuadernos de la Casa Chata, 126.

Díez-Canedo, Aurora (1985). "Dos novelas históricas del siglo XIX en el sureste de México. Lágrimas del corazón y Antón Pérez". En Aurora Díez-Canedo, Jorge Mario Martínez y Jorge Eduardo Tappan. Literatura, relato popular y religiosidad en el sureste de México. México: CIESAS Sureste, Cuadernos de la Casa Chata, 126, pp. 1-32.

Geertz, Clifford (1997). El antropólogo como autor. Barcelona: Paidós.

Gornick, Vivian (2018). Apegosferoces. Madrid: Sexto Piso. Gutiérrez Alfonzo, Carlos (2010). "Relatos en la frontera". En Carlos Gutiérrez Alfonzo (coord.), Representaciones 
en frontera. México: Juan Pablos Editor, Universidad de Ciencias y Artes de Chiapas, pp. 151-223.

Gutiérrez Alfonzo, Carlos (2017). "La frontera ChiapasGuatemala como objeto de estudio de la antropología. Años ochenta del siglo XX". En Revista Pueblos y Fronteras Digital, 12(24), 163-182.

Gutiérrez Alfonzo, Carlos (2018). "Cuando se encuentra la palabra: voces”. En Daniel Domínguez Cuenca, Carlos Gutiérrez Alfonzo y Norma Esther García Meza (coords.), Tales somos en el camino de la palabra: reflexiones sobre literatura. Xalapa: Universidad Veracruzana, pp. 47-72.

Kauffer, Edith (1997). "Refugiados guatemaltecos y conformación de la frontera sur de Chiapas en los años ochenta”. En Philippe Bovin (coord.), Las fronteras del Istmo. Fronteras y sociedades entre el sur de México y América Central. México: CIESAS, Centro Francés de Estudios Mexicanos y Centroamericanos, pp. 155-162.

Martínez, Jorge Mario (1985). "El conejo Juan y otros relatos (una contribución al estudio de lo cómico en la narrativa popular mexicana". En Aurora Díez-Canedo, Jorge Mario Martínez y Jorge Eduardo Tappan. Literatura, relato popular y religiosidad en el sureste de México. México: CIESAS Sureste, Cuadernos de la Casa Chata, 126, pp. 33-94.

Martínez Luna, Esther (2018). "La explicación de la historia en materia literaria”. En Esther Martínez Luna (coord.), Dimensiones de la cultura literaria en México (1800-1850). Modelos de sociabilidad, materialidades, géneros y tradiciones intelectuales. México: UNAM, pp. 3-17.

Medina Hernández, Andrés (1994). "Ricardo Pozas en la trama de la antropología mexicana”. En La Palabray el Hombre, 91, julio-septiembre, 21-67.

Monterroso, Augusto (1993). Los buscadores de oro. México: Alfaguara.

Morales Bermúdez, Jesús (1987). Memorial del tiempo o vía de las conversaciones. México: Katún, Instituto Nacional de Bellas Artes.
Morales Bermúdez, Jesús (1994). "De oralidad y escritura”. En XXII Mesa Redonda de la Sociedad Mexicana de Antropología. Tuxtla Gutiérrez: Instituto Chiapaneco de Cultura, Sociedad Mexicana de Antropología, pp. 189-201. Morales Bermúdez, Jesús (1997). Aproximaciones a la poesía y la narrativa de Chiapas. Tuxtla Gutiérrez: Universidad de Ciencias y Artes de Chiapas.

Morales Bermúdez, Jesús (2005). "La frontera sur en su literatura. Notas para su estudio”. En Alain Basail Rodríguez (coord.), Fronteras des-bordadas. Ensayos sobre la frontera sur de México. México: Universidad de Ciencias y Artes de Chiapas, Juan Pablos Editor, pp. 53-85.

Morales Bermúdez, Jesús (coord.) (2019). Memoria, selva $y$ literatura: entre el mito y el conocimiento. México: Universidad de Ciencias y Artes de Chiapas, Juan Pablos Editor.

Navarrete, Carlos (1984). Los arrieros del agua. México: Katún. Paniagua, Héctor Eduardo (2011). Fiesta de pájaros. Edición crítica de Ignacio Ruiz Pérez. Tuxtla Gutiérrez: Universidad de Ciencias y Artes de Chiapas.

Quijano, Mónica (2018). "Acerca de la Historia de las literaturas en México. Siglos XIX, XX y XXI”. En Esther Martínez Luna (coord.), Dimensiones de la cultura literaria en México (1800-1850). Modelos de sociabilidad, materialidades, géneros y tradiciones intelectuales. México: UNAM, pp. XXV-XXXVI.

Reyes Ochoa, Alfonso (1984). La cena y otras historias. México: Fondo de Cultura Económica, Secretaría de Educación Pública.

Rivera Garza, Cristina (2016). Había mucha neblina o humo o no sé qué: Caminar con Juan Rulfo. México: Mondadori.

Rossi, Alejandro (1996). Manual del distraído. México: Fondo de Cultura Económica.

Schaeffer, Jean-Marie (2013). Pequeña ecología de los estudios literarios. iPor qué y cómo estudiar literatura? México: Fondo de Cultura Económica.

Villafuerte, Nadia (2008). ¿Te gusta el látex, cielo? México: Fondo Editorial Tierra Adentro. 